\title{
CYBERSECURITY IMPACTS FOR ARTIFICIAL INTELLIGENCE USE WITHIN INDUSTRY 4.0
}

\author{
Maurice DAWSON \\ mdawson2@iit.edu \\ ILLINOIS INSTITUTE OF TECHNOLOGY, CHICAGO, USA
}

\begin{abstract}
In today's modern digitizing manufacturing landscape, new and emerging technologies can shape how an organization can compete, while others will view this as a necessity to survive as manufacturing has been identified as a critical infrastructure. Universities struggle to hire university professors that are adequately trained or willing to enter academia due to competitive salary offers in the industry. Meanwhile, the demand for fields such as Artificial Intelligence, data science, and cybersecurity continuously rises with no foreseeable drop in demand in the next several years. This results in organizations deploying technologies with an inadequate staff that understands what new cybersecurity risks they are introducing into the company. Examined are how organizations can potentially mitigate some of the risk associated with integrating these new technologies and developing their workforce to be better prepared for looming changes in technological skill need. With the over a $10 \%$ growth in organizations deploying Artificial Intelligence, the current cybersecurity workforce needs are over half a million. A struggle to find a viable workforce this research paper aims to serve as a guide for Information Technology managers and senior management to foresee the cybersecurity risks that will result from the incorporation of these new technological advances into the organization.
\end{abstract}

\section{KEYWORDS:}

Artificial intelligence, cybersecurity, workforce, risk management

\section{Introduction}

In the Gartner's 2019 Chief Information Officer (CIO) Agenda survey shows demand for Artificial Intelligence (AI) implementation within businesses that grew from $4 \%$ to $14 \%$ (Goasduff, 2019). This survey represented over 80 organizations and 3,000 respondents, which shows the transition to a new era in Information Technology (IT) as digitalization continues quickly (Garfinkel, 2018). Meanwhile, in fields such as cybersecurity within the United States (US), websites such as CyberSeek show over 500,000 total cybersecurity openings with the top three titles being cybersecurity 
engineering, cybersecurity analyst, and network engineer / architect (CyberSeek, n.d.). The supply of these workers is deficient. Reviewing the cybersecurity workforce supply and demand ration for a national average is 2.0, while the national average for all jobs is 4.0 in the US (CyberSeek, n.d.).

Researchers looked into technical skills needed, and data science management was one of the five in the group for Industry 4.0 (Pinzone, Fantini, Perini, Garavaglia, Taisch \& Miragliotta, 2017). For data science management, some of the identified skills were data storage, the cloud of computing, and developing applications in languages such as Python (2017). For this skill, there is no mention of secure software in developing these needed data science applications. Over seventy-five percent of vulnerable are found within the code (Murtaza, Khreich, Hamou-Lhadj \& Bener, 2016). Nowhere in this skill needs report summarization in the first four roles was the mention of secure use of these tools. However, in Information Technology (IT) and Operations Technologies (OT) within industrial automation, cybersecurity is mentioned about data privacy, safety, and security management.

\section{Industry 4.0}

Manufacturing has undergone many industrial revolutions that have changed the ability to produce goods, as shown in Figure no. 1. Technological advances have made these industrial revolutions possible. The third industrial revolution introduced computers and automation. Industry 4.0 is often referred to as the fourth industrial revolution is cyber-physical systems. The need for further automation and unparalleled levels of data exchange brings about multiple changes. These changes come in the form of Internet-enabled hyperconnected devices such as the Internet of Things (IoT) and the Internet of Everything (IoT). This digital revolution is changing the manufacturing industry in terms of what can be accomplished.

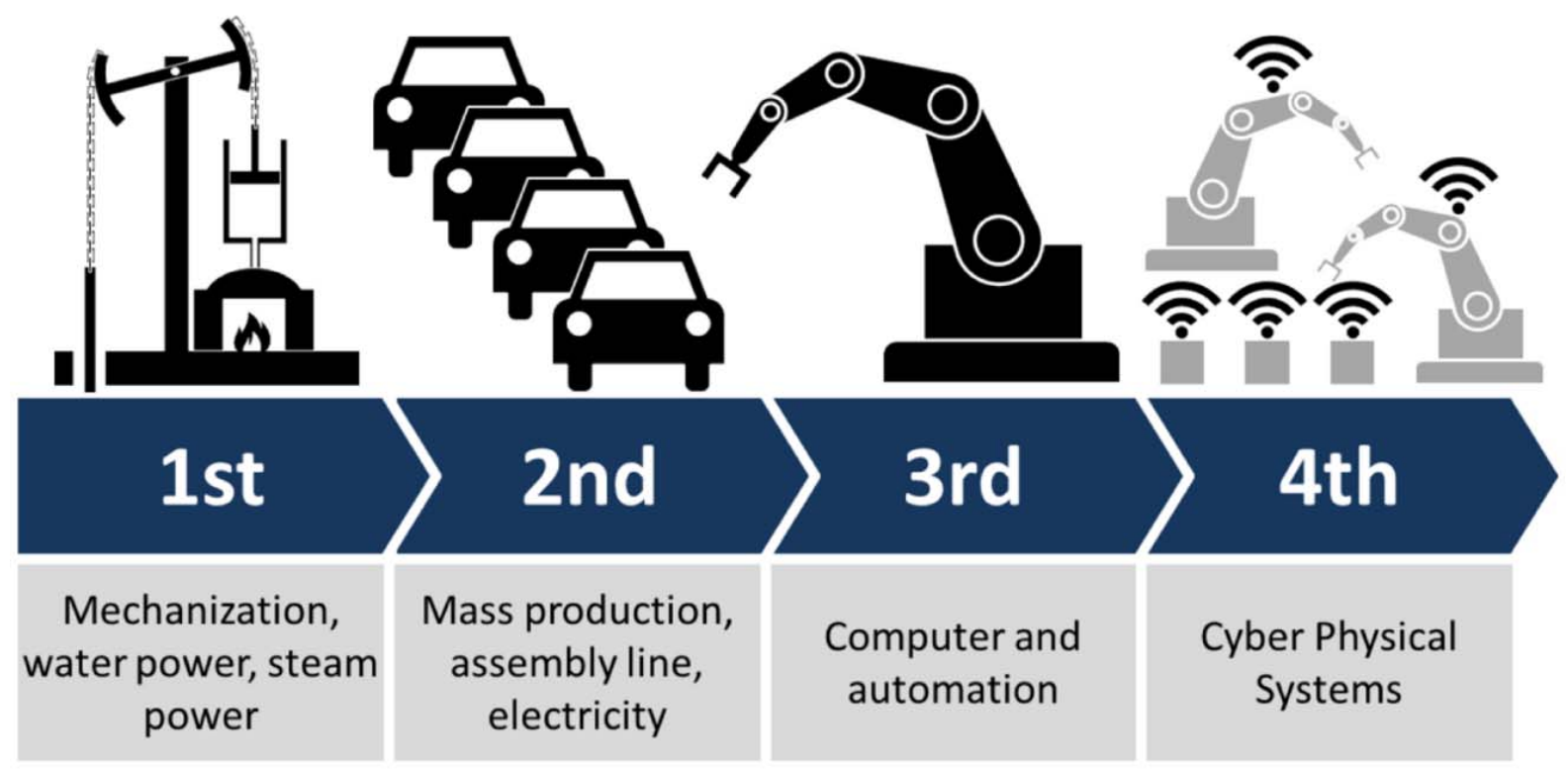

Figure no. 1: Industrial revolutions

(Source: Reprinted from Industry 4.0, by Wikipedia, 2018)

As many industries look to incorporate IoT and other Internet-enabled devices, manufacturing is but one of them.
While making this change, certain places such as the United Kingdom (U.K.) reported eighty-five participants falling 
victim to cyber-attacks (Ambrose, 2018). In the Middle East and Africa, the attacks have ranged from the leak of online dating profiles to oil refineries in Saudi Arabia. With cyber-attacks continuing to rise from year to year, there is a push to incorporate another sophisticated technology into manufacturing.

\section{The promise of AI in manufacturing}

In 2016 there were two reports from the White House describing the promise and the future of $\mathrm{AI}$ as it affects automation and economy (White House, 2016a; White House, 2016b). Specifically, some of the growth could be achieved by adopting technologies such as robots and systems that allow for massive improvements in the supply chain (White House, 2016a). The use of AI in Industry 4.0 based manufacturing systems is still emerging, and lots of work to be done to ensure proper development and implementation (Lee, Davari, Singh \& Pandhare, 2018). The goal is to produce more goods with fewer employed workers in the facility, which would enable economic growth globally. The National Institute of Standards and Technology (NIST) shows that significant advances in AI are a rise in productivity, efficient resource use, and increased creativity. However, the downside was the negative impact on the job and helping raise inequality.

\section{Evolving environments}

With organizations pushing for more connectivity and resulting in more complexity amongst hyperconnected systems, then the leadership must understand what the results are for organizations. As the push for a competitive edge requires more data so that our data scientists within the organization can perform statistical analysis to reveal how the information could be harnessed for the competitive edge, it becomes essential to consider the security implications of tool adaptation. The Fourth
Industrial Revolution consists of high levels of automation and unparalleled data exchange levels with unknown security risks (Dawson, 2018).

With events such as Coronavirus Disease (COVID-19), remote work has been strongly encouraged in some metropolitan regions within the U.S. This has increased the need for social distancing to keep employees safe, remote system management, virtual collaboration, and an expansion of cloud computing services. With systems already poorly protected, this added layer of technical work only adds to the threat landscape. Researchers debate how the COVID-19 crisis is challenging technology and how it could accelerate the revolution (IEEE, 2020). The number of cybersecurity attacks has risen since the global pandemic includes even attacks on the World Health Organization (WHO, 2020). Overall attacks rose by six times the usual levels for hacking and phishing attempts (Muncaster, 2020). These have been felt among all industries, from manufacturing to healthcare.

\section{Understanding the risks}

Organizational cybersecurity risks for AI fall into three areas (see Table no. 1). The first area is people who can be associated with inadequately trained personnel. Inadequate training can lead to falling for deepfakes and allowing authentication to rely solely on stored credentials that another user could obtain through circumvention. Misplaced trust is yet another result of a corporate roll-out plan that is not inclusive and does not account for issues that will come up for those who are ultimately impacted by the implementation of this technology. The second area of risk can is in the process. There needs to be proper automation of processes that incorporate proper security controls. If there are poor security controls in the AI to include the overall manufacturing systems, this will increase the threat landscape. The last area 
of risk is technology. The technology being implemented needs to undergo full system testing, which includes the testing in the sandbox environment to deployment. Periodic testing needs to occur to ensure that newly released and older Common
Weakness Enumerations (CWEs) do not affect the system's security posture. However, testing falls also into the risk of the process as the organization would need to have selected or designed a process that consists of frequent and in-depth testing.

Table no. 1

Organizational cybersecurity risks for AI

\begin{tabular}{|l|l|}
\hline Area of Risk & General Risk Description \\
\hline People & $\begin{array}{l}\text { Inadequately trained personnel using } \\
\text { technology for operational use. }\end{array}$ \\
\hline Falling for deepfakes. \\
\hline Malicious use of Al. \\
\hline Misplaced trust. \\
\hline Improper execution of the selected process. \\
\hline Mrocess & $\begin{array}{l}\text { Al automation of critical points for } \\
\text { identification, authentication, and } \\
\text { authorization. }\end{array}$ \\
\hline $\begin{array}{l}\text { Poor automation of processes that include } \\
\text { security. }\end{array}$ \\
\hline $\begin{array}{l}\text { Incorporating an incorrect security } \\
\text { framework. }\end{array}$ \\
\hline $\begin{array}{l}\text { Built-in software bugs, flaws, and } \\
\text { vulnerabilities. }\end{array}$ \\
\hline Poor interoperability of Al into systems. \\
\hline Ineffective system security to safeguard Al. \\
\hline Supply chain risks. \\
\hline Inadequate testing. \\
\hline
\end{tabular}

In the area of risk, it is essential to note that people develop even the AI, so having component developers means a lot to how the AI will ultimately behave. The design of complex algorithms that give life to the system is solely dependent upon the skills of that engineer. For years, people have wrestled with AI's capabilities and exactly where that would lead society (Minky, 1982). The thing that researchers did not place enough thought into was how to equip those ultimately responsible for the AI systems to defend them. For the staff that will manage these manufacturing floors, it is imperative that they understand IoT and how AI ultimately changes this ecosystem.

Currently, in the majority of industrial engineering courses, cybersecurity is not in the curriculum, after reviewing numerous programs in managerial education, such as advanced degrees such as the Master of Business Administration (MBA). A review of over forty MBA programs shows that the technical coursework may have a course that deals with Information Systems (IS) and a small section dedicated to cybersecurity in a high-level generalized delivery. This is inadequate and not focused enough to have those insights on future challenges.

Training is another critical factor in executing organizational processes regarding technology (Umble, Haft \& Umble, 2003). For any selected process to work effectively and efficiently, those responsible for carrying out the process should have been trained and aware of the actual processes. 
It will be already challenging enough to insert new changes into the organization, but this must be done in a manner that allows retention.

For designing the AI, developing security throughout the lifecycle is vital, as displayed in Figure no. 2. This means there needs to be well-defined requirements and interactive testing of software. Doing this allows for proper inspection of the code to ensure there are no backdoors, dead code that allows for exploitation, or hidden malicious programs.

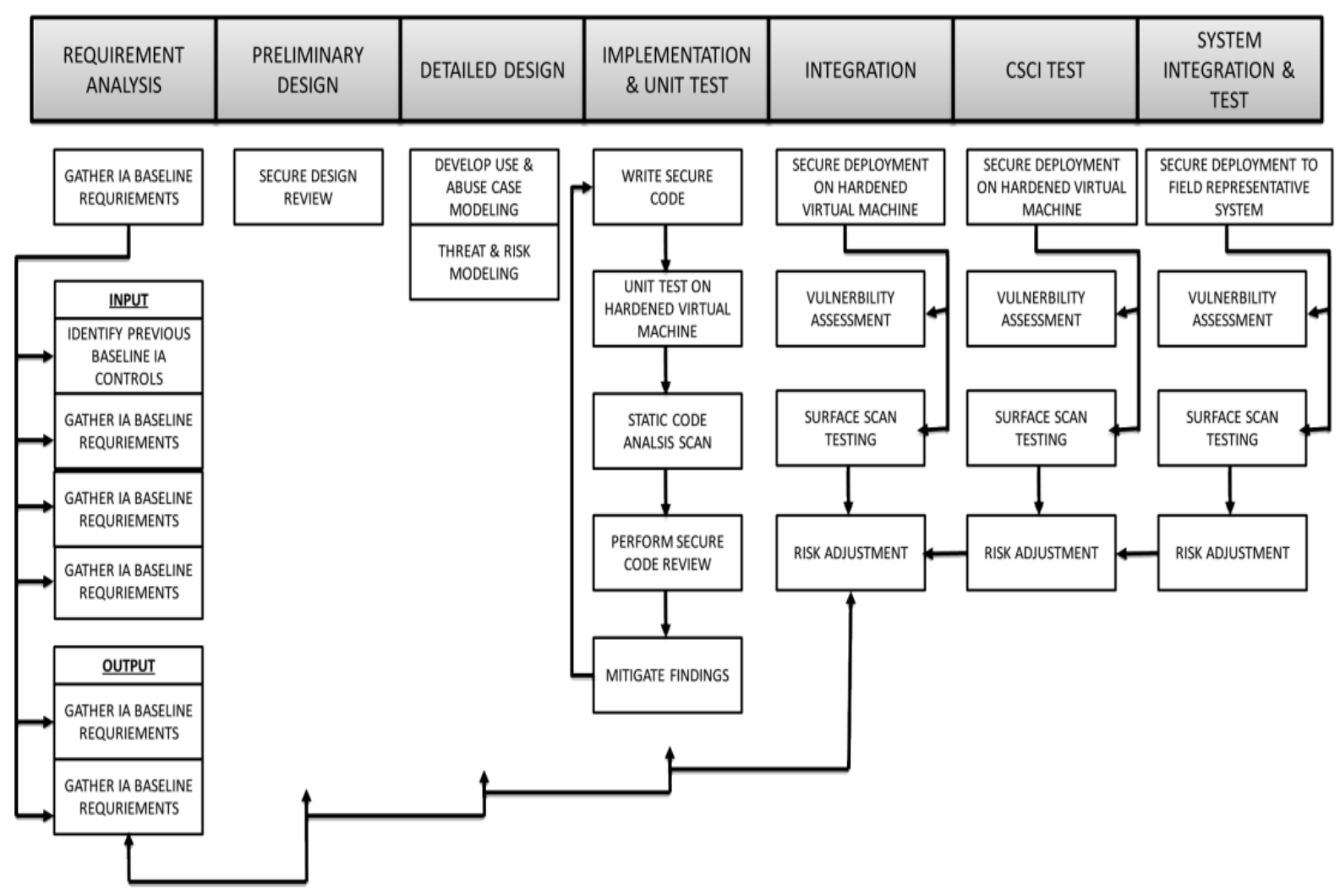

Figure no. 2: Secure software development process

Technology has been identified as the final area of risk to address. As managers and senior leader leaders wish to add these technologies, several things can be done. Supply chain and the acquisition of systems is a risk within technology. Not knowing the origin of a particular piece of code or hardware poses a risk as the quality or security of that specific item may create vulnerability for the more extensive system. Imagine the actual algorithm being developed by a nation-state that ends up rerouting critical data or causing a catastrophic event at a facility such as fire due to overheating.

\section{Importance of manufacturing in} U.S.

As of February 2019, an Executive Order (EO) issued maintaining leadership in AI (Trump, 2019). It calls for promoting AI research and innovation while protecting American AI. At the same time, Putin wants to be the global leader for AI and use it in AI-driven asymmetric warfare (Polyakova, 2019). However, after investigating the investments to AI, Russia falls far behind countries like China. Countries are scrambling to ensure they are global players in AI with significant investments, while Nevertheless, cybersecurity attacks 
on the manufacturing industry could be devastating.

The U.S. Bureau of Economic Analysis (BEA) data from 2010 to 2019 shows the gross output for multiple industries. In Figure no. 3 the industries evaluated are the following:

1. Manufacturing;

2. Agriculture, forestry, fishing, and hunting;

3. Educational services, health care, and social assistance;

4. Construction;

5. Utilities;

6. Transportation and warehousing;

7. Mining;

8. Information.
The year 2019 shows manufacturing being $16.57 \%$ of total gross output (U.S. Bureau of Economic Analysis, 2020). In 2018 that percent was $16.98 \%, 2017$ was $16.86 \%$, 2016 was $16.9 \%$, and 2015 was $17.73 \%$ (U.S. Bureau of Economic Analysis, 2020). This data provided by the BEA shows that manufacturing is significant to the gross output for the U.S. Meaning that if this industry becomes under attack, it could result in catastrophic events such as loss of critical Intellectual Property (IP), manufacturing output, and overall lower gross output that would lower the total output by an estimated $16 \%$.

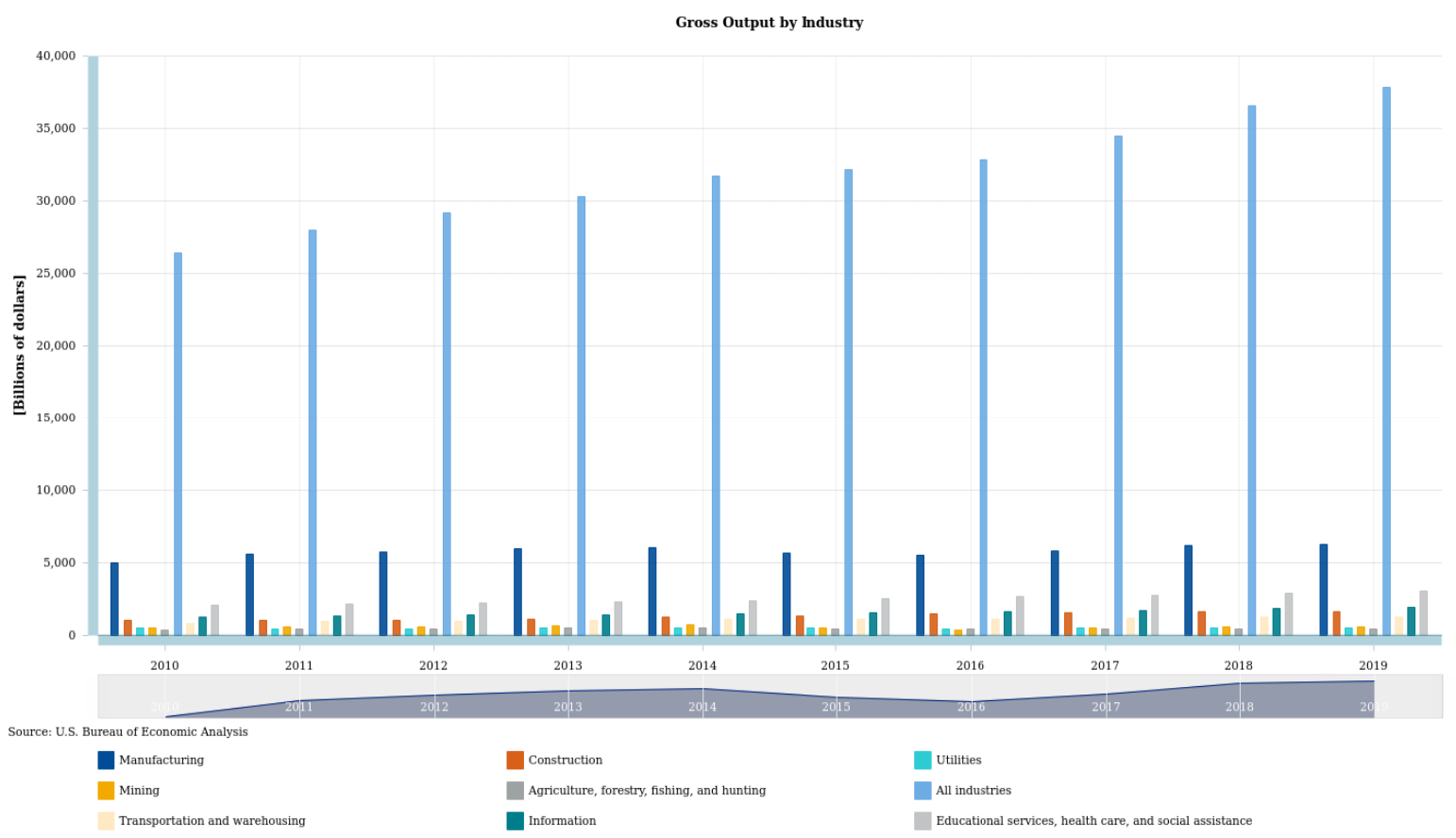

Figure no. 3: Gross Output by Industry

(Source: U.S. Bureau of Economic Analysis, 2020)

\section{Conclusions}

Today's modern manufacturing IoT environment requires organizations to manage expectations and risks as they relate to cybersecurity effectively. Organizations need to consider how they fully utilize technologies such as data science while protecting the data that is being analyzed. In this paper, we examined some risks associated with organizational uses for AI. Understanding cyber defense and cyber offensive viewpoints may yet provide some insight into how organizations should conduct tests to review the threat landscape (Dawson, 2020). 
In this submission, reviewed were three areas of risks that need to be managed for implementation of AI into Industry 4.0. Reviewing data from BEA proves the significance of manufacturing in the U.S. industry to include the impact of the cybersecurity vulnerabilities that are not managed appropriately. The conclusion is that as the increased use of AI in critical industries such as manufacturing, it is essential to ensure that proper security controls are in place to thwart any possible threat, whether internal or external (Gill, 2019).

\section{REFERENCES}

Ambrose, J. (2018, April 23). Half of UK manufacturers fall victim to cyber attacks, available at: https://www.telegraph.co.uk/business/2018/04/22/half-uk-manufacturersfallvictim-cyber-attacks/, accessed on 04 June 2020.

CyberSeek. (n.d.). Cybersecurity Supply and Demand Heat Map, available at: https://www.cyberseek.org/heatmap.html, accessed on 15 March 2020.

Dawson, M. (2018). Cyber security in industry 4.0: The pitfalls of having hyperconnected systems. Journal of Strategic Management Studies, Vol. 10, Issue 1, 19-28.

Dawson, M. (2020). National Cybersecurity Education: Bridging Defense to Offense. Land Forces Academy Review, Vol. 25, Issue 1, 68-75.

Garfinkel, J. (2018, October 16). Gartner Survey of More Than 3,000 CIOs Reveals that Enterprises Are Entering the Third Era of IT, available at: https://www.gartner.com/ en/newsroom/press-releases/2018-10-16-gartner-survey-of-more-than-3000-cios-reveals-thatenterprises-are-entering-the-third-era-of-it, accessed on 05 February 2020.

Gill, A.S. (2019). Artificial intelligence and international security: the long view. Ethics \& International Affairs, Vol. 33, Issue 2, 169-179.

Goasduff, L. (2019, September 12). Top Trends on the Gartner Hype Cycle for Artificial Intelligence, available at: https://www.gartner.com/smarterwithgartner/top-trendson-the-gartner-hype-cycle-for-artificial-intelligence-2019/, accessed on 15 March 2020.

IEEE. (2020, June 4). How COVID-19 is Affecting Industry 4.0 and Innovation, available at: https://transmitter.ieee.org/how-covid-19-is-affecting-industry-4-0-and-thefuture-of-innovation/, accessed on 08 June 2020.

Lee, J., Davari, H., Singh, J., \& Pandhare, V. (2018). Industrial Artificial Intelligence for industry 4.0-based manufacturing systems. Manufacturing letters, Vol. 18, 20-23.

Minsky, M.L. (1982). Why people think computers can't. AI magazine, Vol. 3, Issus 4, 3.

Muncaster, P. (2020, April 1). Cyber-Attacks Up 37\% Over Past Month as \#COVID19 Bites, available at: https://www.infosecurity-magazine.com/news/cyberattacks-up-37-overpast-month/, accessed on 05 June 2020.

Murtaza, S.S., Khreich, W., Hamou-Lhadj, A., \& Bener, A.B. (2016). Mining trends and patterns of software vulnerabilities. Journal of Systems and Software, Vol. 117, 218-228.

Pinzone, M., Fantini, P., Perini, S., Garavaglia, S., Taisch, M., \& Miragliotta, G. (2017, September). Jobs and skills in Industry 4.0: An exploratory research. IFIP International Conference on Advances in Production Management Systems (pp. 282-288). Cham, Switzerland: Springer.

Polyakova, A. (2019, October 25). Weapons of the weak: Russia and AI-driven asymmetric warfare, available at: https://www.brookings.edu/research/weapons-of-the-weakrussia-and-ai-driven-asymmetric-warfare/, accessed on 07 June 2020.

Trump, D.J. (2019). Executive order on maintaining American leadership in artificial intelligence. Federal Register: White House, Vol. 84, No. 31, 3967-72. 
U.S. Bureau of Economic Analysis. (2020). Interactive Access to Industry Economic Accounts Data: GDP by Industry, available at: https://apps.bea.gov/iTable/iTable. cfm?reqid=51\&step=1\#reqid=51\&step=1, accessed on 07 June 2020.

Umble, E.J., Haft, R.R., \& Umble, M.M. (2003). Enterprise resource planning: Implementation procedures and critical success factors. European journal of operational research, Vol. 146, Issue 2, 241-257.

White House. (2016a). Artificial Intelligence, Automation, and the Economy. Executive Office of the President, available at: https://obamawhitehouse.archives.gov/sites/ whitehouse.gov/files/documents/Artificial-Intelligence-Automation-Economy.PDF, accessed on 07 June 2020.

White House. (2016b). Preparing for the future of Artificial Intelligence, available at: https://obamawhitehouse.archives.gov/sites/default/files/whitehouse files/microsites/ostp/NS TC/preparing for the future of ai.pdf, accessed on 07 June 2020.

Wikipedia. (2018, June 19). Industry 4.0, available at: https://en.wikipedia.org/ wiki/Industry 4.0, accessed on 17 May 2020.

World Health Organization. (2020, April 23). WHO reports fivefold increase in cyber attacks, urges vigilance, available at: https://www.who.int/news-room/detail/23-04-2020who-reports-fivefold-increase-in-cyber-attacks-urges-vigilance, accessed on 07 June 2020. 